\title{
Biodiversity, seasonal abundance, and distribution of blackflies (Diptera: Simuliidae) in six different regions of Thailand
}

Wichai Srisuka ${ }^{1}$, Hiroyuki Takaoka², Yasushi Otsuka ${ }^{3}$, Masako Fukuda ${ }^{4}$, Sorawat Thongsahuan ${ }^{5}$, Kritsana Taai ${ }^{6}$ and Atiporn Saeung ${ }^{7^{*}}$

\begin{abstract}
Background: Blackflies are an important medical and veterinary group of small blood-sucking insects. Ninety-three blackfly species have been reported in Thailand. However, information on their biodiversity and population dynamics in each region is lacking. The main aim of this study was to assess the regional biodiversity, seasonal abundance and distribution of blackflies in six eco-geographically different regions in the country.

Methods: Blackfly larvae and pupae were sampled monthly from 58 sites between May 2011 and April 2013. Diversity parameters, seasonal abundance, regional distribution and frequency of species occurrence in stream sites were analyzed.

Results: A total of 19,456 mature larvae representing 57 species, and belonging to six subgenera in the genus Simulium Latreille (s.I.), were found. The five predominant taxa were S. fenestratum (8.6\%), the S. asakoae complex (8.3\%), S. nakhonense (7.5\%), the $S$. siamense complex (7.4\%) and the $S$. doipuiense complex (6.7\%). The most frequent taxa at all sites were the S. asakoae complex (84.5\%), followed by S. fenestratum (82.8\%), the S. siamense complex (75.9\%), S. decuplum (60.3\%), S. nakhonense (58.6\%) and the S. tani complex (48.3\%). The richness of regional species was highest (40 species) in the north and predominated in the cold season. However, blackflies in the south predominated during the hot season. The highest numbers of blackflies collected from central, northeastern, eastern and western regions of the country were observed in the rainy season. Overall, the mean number of blackflies collected across the six regions during the rainy and cold season had no statistically significant difference, but it differed significantly in the hot season.
\end{abstract}

Conclusions: Blackflies in Thailand were surveyed in all three seasons across six geographical regions. These findings demonstrated that blackfly communities at each stream site varied with seasonality, and the regional relative abundance of blackflies differed markedly in the hot season. It was also found that the occurrence and distribution of blackflies in each region were associated strongly with elevation.

Keywords: Blackfly, Simulium, Biodiversity, Shannon diversity index, Regional distribution, Thailand

\footnotetext{
* Correspondence: atisaeung.noi@gmail.com

${ }^{7}$ Department of Parasitology, Faculty of Medicine, Chiang Mai University,

Chiang Mai 50200, Thailand

Full list of author information is available at the end of the article
} 


\section{Background}

Blackflies (Diptera: Simuliidae) are distributed widely in all zoogeographical regions and found almost everywhere with running water that is suitable as a habitat for their aquatic stages [1]. Larvae and pupae are aquatic, and attach themselves to various submerged objects in many types of lotic environments, ranging from large rivers to tiny spring-fed trickles, and from swift currents to water that barely moves [2]. The choice of habitat usually varies between species. Due to their bloodsucking habits, adult females of certain blackfly species are of a medical and veterinary importance. Blackflies have been considered as vectors of many pathogens, such as filarioid nematodes of the genus Onchocerca in humans, cattle and deer, the genus Dirofilaria in bears, the genus Splendidofilaria in ducks; blood protozoans of the genera Leucocytozoon and Trypanosoma in birds; and viruses (rift valley fever, vesicular stomatitis) in horses and cattle; as well as chlamydial bacteria that cause blindness in sheep and abortion in cattle [1-3]. Furthermore, blackfly bites can cause other severe problems in humans, since they frequently inflict pain, localized swelling, chronic dermatitis and inflammation accompanied by intense irritation that lasts for several days or even weeks [2].

In Thailand, a total of 93 blackfly species belonging to six subgenera, including Asiosimulium, Daviesellum, Gomphostilbia, Montisimulium, Nevermannia and Simulium, have been reported ([4], W. Srisuka, unpublished observations), with most new blackfly species being discovered in the northern part of the country. Remarkably, although the above information reflects rich species diversity, there are only a few reports of simuliids from other regions in Thailand, for instance, S. otsukai, S. thongsahuani, S. datfaense and $S$. trangense, in the south [5-7]; S. vanellum from the west [8], S. atipornae and $S$. lomkaoense from central Thailand [9, 10]; and $S$. kuvangkadilokae from the northeast [11, 12]. Notably, there were no reports on regional biodiversity, seasonal abundance or distribution of blackflies in macro-scale areas of Thailand, apart from only the hotspot area in the tropical rainforest at Doi Pha Hom Pok National Park, in the northern region [13]. Additionally, human-biting blackfly species are found in large numbers, and cause irritation in domestic environments and to indigenous people and tourists [14], thus, most previous studies focused on the annual biting activity of adult females at Doi Inthanon and Doi Suthep-Pui National Park as well as in the village of Ban Pang Faen, Chiang Mai Province, northern Thailand [14-17].

Hence, the main aim of this study was to determine the seasonal abundance and dynamics of blackflies in six geographically and ecologically different regions of Thailand.

\section{Methods}

\section{Study areas and sampling}

This study was carried out at 58 fixed-stream sites in 41 provinces in six regions across Thailand, including 15, $10,10,7,8$ and 8 sites in the north (9 provinces), central (7 provinces), northeast ( 7 provinces), east ( 5 provinces), west (5 provinces) and south (8 provinces), respectively (Fig. 1, Additional file 1: Table S1). A total of 696 collections were made in this study (12 at each 58 fixedstream sites at monthly intervals) from May 2011 to April 2013 which covered all seasons for each region. Larvae and pupae were hand sampled using fine forceps from available substrates in streams, such as fallen leaves, mud or rock surfaces, and trailing grasses. Fortyfive minutes exactly were spent for the collection of larvae and pupae by the same person (one person) at each stream site. Larvae were preserved in $80 \%$ ethanol. The substrates were cut into pieces so that each part harboured a single pupa. Matured pupae were maintained individually in a plastic tube $(10 \mathrm{~cm}$ long and $1.7 \mathrm{~cm}$ in diameter) with very little water at the bottom until adults emerged. After emergence, adult flies were kept alive in the same tube for at least $24 \mathrm{~h}$, to secure hardening and colouring of their body and legs. Adult flies, associated with their pupal exuviae, were used to confirm the species identification of the larvae.

\section{Meteorology and regions}

The classification of the season in each region follows the Thai Meteorological Department, which bases its records on rainfall and air temperature data. Thus, each year is divided climatically into three seasons in the following regions: North region, with hilly and mountainous areas ranging from 392 to $2210 \mathrm{~m}$ in height, total rainfall of approximate $1287 \mathrm{~mm}$ and an average air temperature of $25{ }^{\circ} \mathrm{C}$; West region, with mostly mountainous areas in the range of $111-560 \mathrm{~m}$ in height, similar to the north, and total rainfall and average air temperature of $1243 \mathrm{~mm}$ and $27.13{ }^{\circ} \mathrm{C}$, respectively; Central region, with largely low-level plains and a few mountains ranging from 167 to $1550 \mathrm{~m}$ high in the northern and western part of the region, with a total rainfall and average air temperature of $1377 \mathrm{~mm}$ and $26.1{ }^{\circ} \mathrm{C}$, respectively; Northeast region, which is a naturally high-level plain called the northeast plateau; Northwest-southeast region, which has Phu Phan Ridge oriented in the northeastern portion that separates this area into two basins, the first one is a large high-level plain in the west and the other smaller and sloped towards the east with an elevation ranging from 110 to $1337 \mathrm{~m}$; this region has a total rainfall and average air temperature of $1589 \mathrm{~mm}$ and $25.1{ }^{\circ} \mathrm{C}$, respectively; East region, which is mountainous in the northeast, and its eastern area is close to the Gulf of Thailand with an 


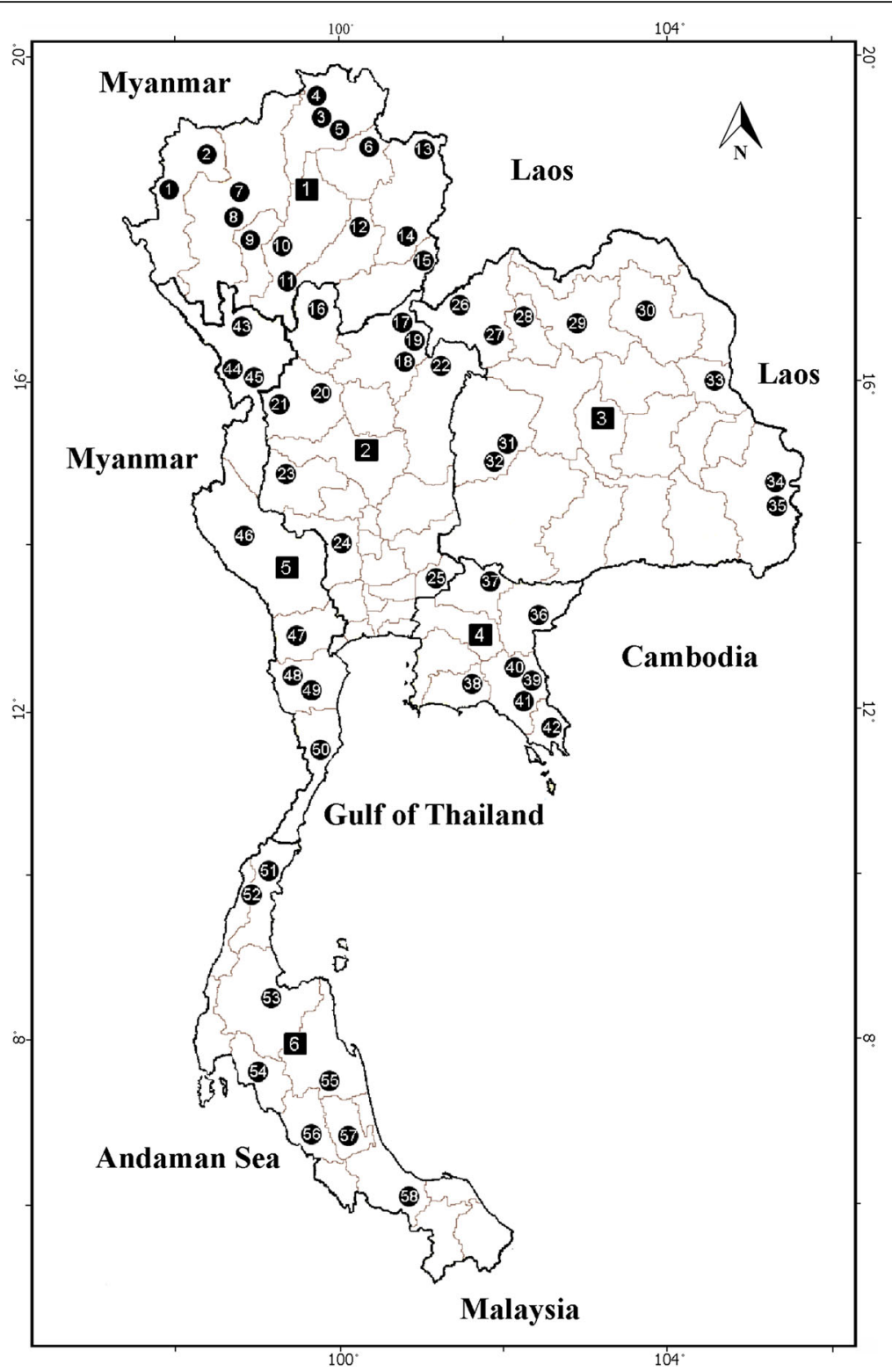

Fig. 1 Map of Thailand showing 58 fixed-stream sites located in 41 provinces where larvae and pupae of blackflies were collected during the two-year study period (May 2011 to April 2013). Details of sampling sites are given in Additional file 1

elevation ranging from 76 to $409 \mathrm{~m}$, and total rainfall and an average air temperature of $2903 \mathrm{~mm}$ and $26.7{ }^{\circ} \mathrm{C}$, respectively; South region, which has a peninsula mountain spine that is very steep. Its eastern area is close to the Gulf of Thailand and its western region near the Andaman Sea. It has an elevation ranging from 111 to $560 \mathrm{~m}$, and total rainfall and an average air temperature of $2601 \mathrm{~mm}$ and $28.9^{\circ} \mathrm{C}$, respectively.

\section{Species identification}

Species identification was based on morphological characteristics of last-instar larvae (matured), pupae and reared adults by using the standard keys of Takaoka \&
Choochote [18], which covered 45 blackfly species, and additional keys that dealt with blackflies in Thailand $[5-12,19-26]$. When formally named species were known to consist of cryptic species, they were referred to as species complex [4]. All specimens of blackflies from this study were deposited at the Entomology Section, Queen Sirikit Botanic Garden (QSBGE), Chiang Mai Province, Thailand.

\section{Data analysis}

Species and relative abundance of mature larvae at each site were recorded. The frequency of blackfly species was calculated by the total number of species occurrence 
divided by the total number of collections and presented in percentages. Stream occurrence (SO) (expressed in percentage) was obtained by calculating the number of sites where a species was taken and dividing it by the total number of sites sampled $(n=58)$. Species diversity and richness (SDR) version 4 [27] and PAST version 3.11 were employed for statistical analyses [28]. Determination and comparison of diversity parameters between regions were calculated using the ShannonWiener index $(\mathrm{H})$, the expected value of $\mathrm{H}(\operatorname{Exp} H)$ and evenness (J'). The species accumulation curves (rarefaction) for regions were also compared. In evaluating species richness, the first order jackknife was used to estimate the number of species presenting in all stream sites. Sample interpopulation was used to estimate the number of species from all regions (696 collections) [27]. Detrended correspondence analysis (DCA) was used to describe the regional distribution of blackfly larvae associated with sampling sites [28]. A ternary plot, based on data of blackfly species in each season and region, was used to interpret seasonal occurrence and abundance [28]. Regional and seasonal differences in blackflies were compared using non-parametric KruskalWallis tests, and $P$-values were adjusted by the Bonferroni correction for post-hoc multiple comparison tests. In addition, the Mann-Whitney $U$-test was used to compare the mean number of blackflies collected from the southern region in two seasons. Statistical analyses were conducted using IBM SPSS statistics, version 24 for Windows (Chicago, SPSS Inc.). Statistical significance was set at $P<0.05$.

\section{Results}

\section{Species composition of blackflies}

A total of 19,456 mature larvae, representing 57 blackfly species of six subgenera, were collected from 58 stream sites across six regions in Thailand (Table 1, Additional file 1: Table S1). At the subgenus level, Simulium was the most diverse (28 species), followed by Gomphostilbia (16 species), Nevermannia (7 species), Asiosimulium (3 species), Montisimulium (2 species) and Daviesellum (1 species). Simulium fenestratum, the $S$. asakoae complex, S. nakhonense, the $S$. siamense complex, and the $S$. doipuiense complex were the five predominant taxa, each representing $8.6 \%(n=1681), 8.3 \%(n=1608), 7.5 \%(n=1451)$, $7.4 \%(n=1441)$ and $6.7 \%(n=1298)$ of those collected. The most frequent taxa at all sites were the $S$. asakoae complex (84.5\%, 49/58 sites), followed by $S$. fenestratum $(82.8 \%, 48 / 58$ sites), the S. siamense complex, (75.9\%, 44/58 sites), S. decuplum (60.3\%, 35/58 sites), S. nakhonense $(58.6 \%, 34 / 58$ sites) and the $S$. tani complex, (48.3\%, 28/58 sites).
Species diversity, richness and distribution pattern

Species diversity and richness of blackflies in each region are shown in Fig. 2, with the highest in the northern region $\left(H=3.1, J^{\prime}=0.8\right)$ and lowest in the southern $\left(H=2.1, J^{\prime}=0.5\right)$. Of 58 stream sites, the Shannon diversity index $(\mathrm{H})$ was highest at Rom Klao (Phitsanulok Province), followed by Doi Phu Kha (Nan Province), Phu Ruea (Loei Province) and Mae Wong (Kamphaeng Phet Province), which represented 2.4, 2.4, 2.3 and 2.3, respectively (Additional file 2: Table S2).

The species accumulation (rarefaction) curves (Fig. 3) showed the expected and observed richness of species occurring in all sites, with a total from all collections being 71 and 57 species, respectively. The expected $( \pm$ SE) and observed species richness were $52 \pm 4.5$ and 40 spp. in northern, $45 \pm 4.1$ and 34 spp. in the central, $38 \pm 2.9$ and $28 \mathrm{spp}$. in western, $31 \pm 2.8$ and $22 \mathrm{spp}$. in northeastern, $25 \pm 4.3$ and $17 \mathrm{spp}$. in southern and $24 \pm 1.8$ and $15 \mathrm{spp}$. in eastern regions, respectively (Fig. 4).

The detrended correspondence analysis (DCA) for the distribution of blackfly species associated with sampling sites (axis 1: eigenvalue 0.8; axis 2: eigenvalue 0.5 ) is presented in Fig. 5. Overall, the $S$. asakoae complex and $S$. fenestratum were common species found in all sites. The distribution of the $S$. doipuiense complex, S. inthanonense, S. fruticosum, S. chiangdaoense, S. maeaiense, S. (Montisimulium) sp., S. vessabutrae, S. atipornae and S. lomkaoense were associated strongly with high elevation (site nos. 8, 13,14, 17, 21 and 22) in the northern and central region, while $S$. quinquestriatum, S. siamense complex, $S$. decuplum and $S$. dentistylum were associated with low elevation (site nos. 20, 23, 24, 25, 29, 30, $31,35,38,40,41$ and 42 ) in the central and northeastern regions. However, S. lampangense, S. weji, S. prayongi and $S$. takense were associated with calcareous waterfalls (site nos. 5, 12 and 44).

\section{Seasonal dynamics}

Overall, S. fenestratum was the dominant species during all three seasons (Additional file 3: Table S3). Almost all of the species in the north were dominant in the cold season, and $S$. chumpornense and S. phayaoense were recorded only during that time, while $S$. pahangense was collected only during the rainy season (Fig. 6, Additional file 3: Table S3). Most species in the central region were discovered in the rainy season, and S. oblongum, S. aureohirtum, S. bullatum, S. phukaense and the S. tani complex were found only during that time, whereas $S$. yongi was only recorded in the cold season (Fig. 6, Additional file 3: Table S3). A greater number of blackflies were collected during the rainy season in the northeastern, eastern and western regions (Figs. 7, 8, Additional file 3: Table S3). Simulium oblongum, S. aureohirtum and S. yuphae were found only during the rainy season in the eastern region, 
Table 1 Total number, relative abundance (percentage), and stream occurrence (SO) of mature larvae of 57 blackfly species collected from 58 sampling sites in six regions in Thailand

\begin{tabular}{|c|c|c|c|}
\hline Species & $\begin{array}{l}\text { Total } \\
\text { collected }\end{array}$ & \%flies & $\% \mathrm{SO}$ \\
\hline Simulium (Asiosimulium) furvum & 34 & 0.2 & 1.7 \\
\hline Simulium (Asiosimulium) oblongum & 487 & 2.5 & 17.2 \\
\hline Simulium (Asiosimulium) wanchaii & 34 & 0.2 & 3.5 \\
\hline Simulium (Daviesellum) pahangense & 9 & 0.1 & 5.2 \\
\hline Simulium (Gomphostilbia) angulistylum complex & 515 & 2.7 & 22.4 \\
\hline $\begin{array}{l}\text { Simulium (Gomphostilbia) asakoae } \\
\text { complex }^{a, b}\end{array}$ & 1608 & 8.3 & 84.5 \\
\hline Simulium (Gomphostilbia) burtoni & 523 & 2.7 & 24.1 \\
\hline Simulium (Gomphostilbia) chiangdaoense & 515 & 2.7 & 10.3 \\
\hline Simulium (Gomphostilbia) chumpornense & 182 & 0.9 & 27.6 \\
\hline Simulium (Gomphostilbia) curtatum & 235 & 1.2 & 12.1 \\
\hline Simulium (Gomphostilbia) decuplum ${ }^{a}$ & 1175 & 6 & 60.3 \\
\hline Simulium (Gomphostilbia) dentistylum & 367 & 1.9 & 37.9 \\
\hline Simulium (Gomphostilbia) duolongum & 450 & 2.3 & 22.4 \\
\hline Simulium (Gomphostilbia) gombakense & 90 & 0.5 & 13.8 \\
\hline Simulium (Gomphostilbia) inthanonense & 753 & 3.9 & 19 \\
\hline Simulium (Gomphostilbia) piroonae & 52 & 0.3 & 1.7 \\
\hline Simulium (Gomphostilbia) kuvangkadilokae & 98 & 0.5 & 3.5 \\
\hline Simulium (Gomphostilbia) parahiyangum & 3 & 0 & 1.7 \\
\hline Simulium (Gomphostilbia) sheilae & 556 & 2.9 & 44.8 \\
\hline $\begin{array}{l}\text { Simulium (Gomphostilbia) siamense } \\
\text { complex }{ }^{a, b}\end{array}$ & 1441 & 7.4 & 75.9 \\
\hline Simulium (Montisimulium) nanense & 51 & 0.3 & 1.7 \\
\hline Simulium (Montisimulium) sp. & 57 & 0.3 & 1.7 \\
\hline Simulium (Nevermannia) aureohirtum & 408 & 2.1 & 22.4 \\
\hline Simulium (Nevermannia) fangense & 22 & 0.1 & 1.7 \\
\hline Simulium (Nevermannia) feuerborni complex & 142 & 0.7 & 8.6 \\
\hline Simulium (Nevermannia) fruticosum & 329 & 1.7 & 17.2 \\
\hline Simulium (Nevermannia) khunklangense & 73 & 0.4 & 1.7 \\
\hline Simulium (Nevermannia) maeaiense & 241 & 1.2 & 8.6 \\
\hline Simulium (Nevermannia) vessabutrae & 7 & 0 & 1.7 \\
\hline Simulium (Simulium) atipornae & 98 & 0.5 & 3.5 \\
\hline Simulium (Simulium) baimaii & 69 & 0.4 & 1.7 \\
\hline Simulium (Simulium) brevipar & 16 & 0.1 & 1.7 \\
\hline Simulium (Simulium) bullatum & 61 & 0.3 & 10.3 \\
\hline Simulium (Simulium) chamlongi & 217 & 1.1 & 20.7 \\
\hline Simulium (Simulium) chiangmaiense & 79 & 0.4 & 3.5 \\
\hline Simulium (Simulium) doipuiense complex ${ }^{\mathrm{b}}$ & 1298 & 6.7 & 25.9 \\
\hline Simulium (Simulium) fenestratum ${ }^{a, b}$ & 1681 & 8.6 & 82.8 \\
\hline
\end{tabular}

similar to species found in the central region. Remarkably, blackflies in the southern region were more dominant during the hot season (Fig. 8, Additional file 3: Table S3). The mean number of blackflies collected across the six regions during the rainy (Kruskal-Wallis test, $H=6.242$, $d f=5, P=0.283$ ) and cold season (Kruskal-Wallis test, $H=8.650, d f=4, P=0.070$ ) had no statistically significant difference, but it differed significantly in the hot season (Kruskal-Wallis test, $H=26.589, d f=5, P<0.0001$ ).

\section{Regional relative abundance Northern region}

The most frequent taxa at all sites were $S$. asakoae complex $(80 \%)$ and S. fenestratum (80\%), followed by $S$. yuphae (73.3\%) and the S. siamense complex, (66.7\%). In addition, the $S$. doipuiense complex, $S$. inthanonense, the $S$. asakoae complex, S. decuplum/S. fenestratum and $S$. chiangdaoense were the five predominant taxa, representing $15.4 \%(n=860), 11.6 \%(n=647), 7.0 \%(n=389), 6.4 \%$ $(n=358)$ and $5.3 \%(n=298)$, respectively (Additional file 4: Table S4). The hot season had significantly lower mean numbers when compared to the rainy (Kruskal-Wallis 


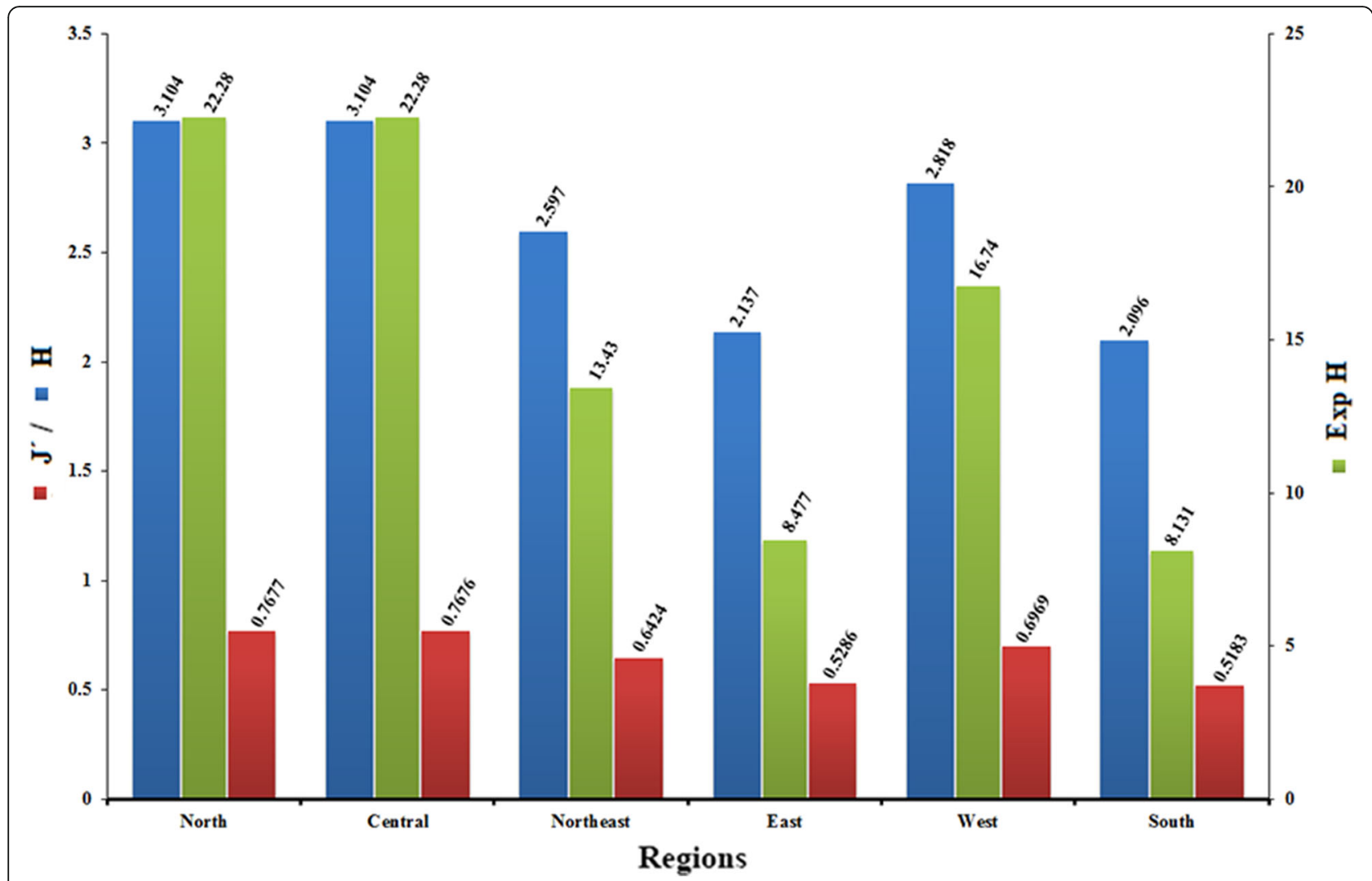

Fig. 2 Diversity parameters, Shannon-Wiener index $(\mathrm{H})$, evenness (Pielou J') and expected H value (Exp H) for blackflies in the six regions of Thailand

test, $H=21.195, d f=2, P=0.021)$ and cold seasons (Kruskal-Wallis test, $H=34.122, d f=2, P<0.0001$ ).

\section{Central region}

The most frequent taxa at all sites were $S$. asakoae complex $(90 \%)$ and the S. siamense complex, (90\%), followed by S. decuplum and S. fenestratum (80\%). Additionally, the S. asakoae complex, the S. doipuiense complex, the S. siamense complex, S. nakhonense and S. ducuplum, were the five predominant taxa, representing 10.3\% $(n=353), 10 \%$ $(n=345), 7.4 \%(n=254), 7.3 \%(n=251)$ and $6.3 \%$ $(n=218)$, respectively (Additional file 5: Table S5).

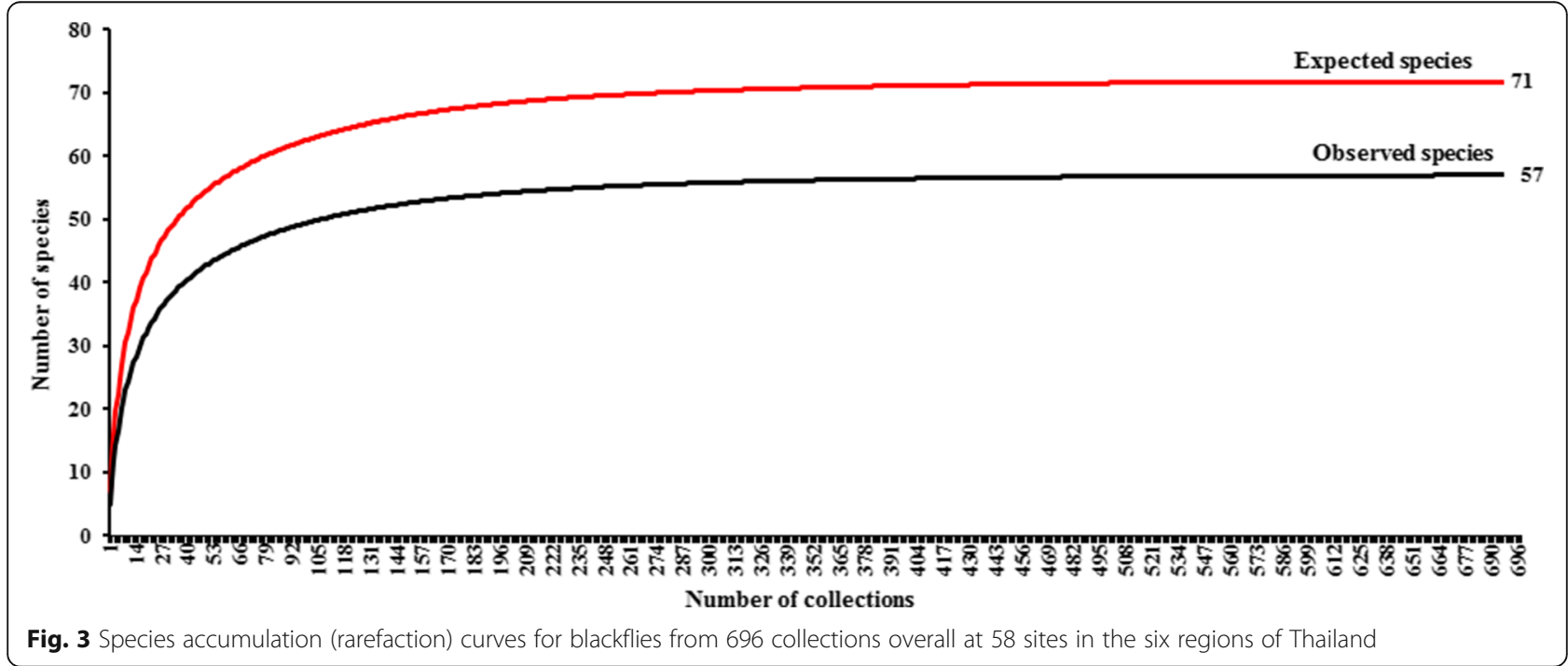



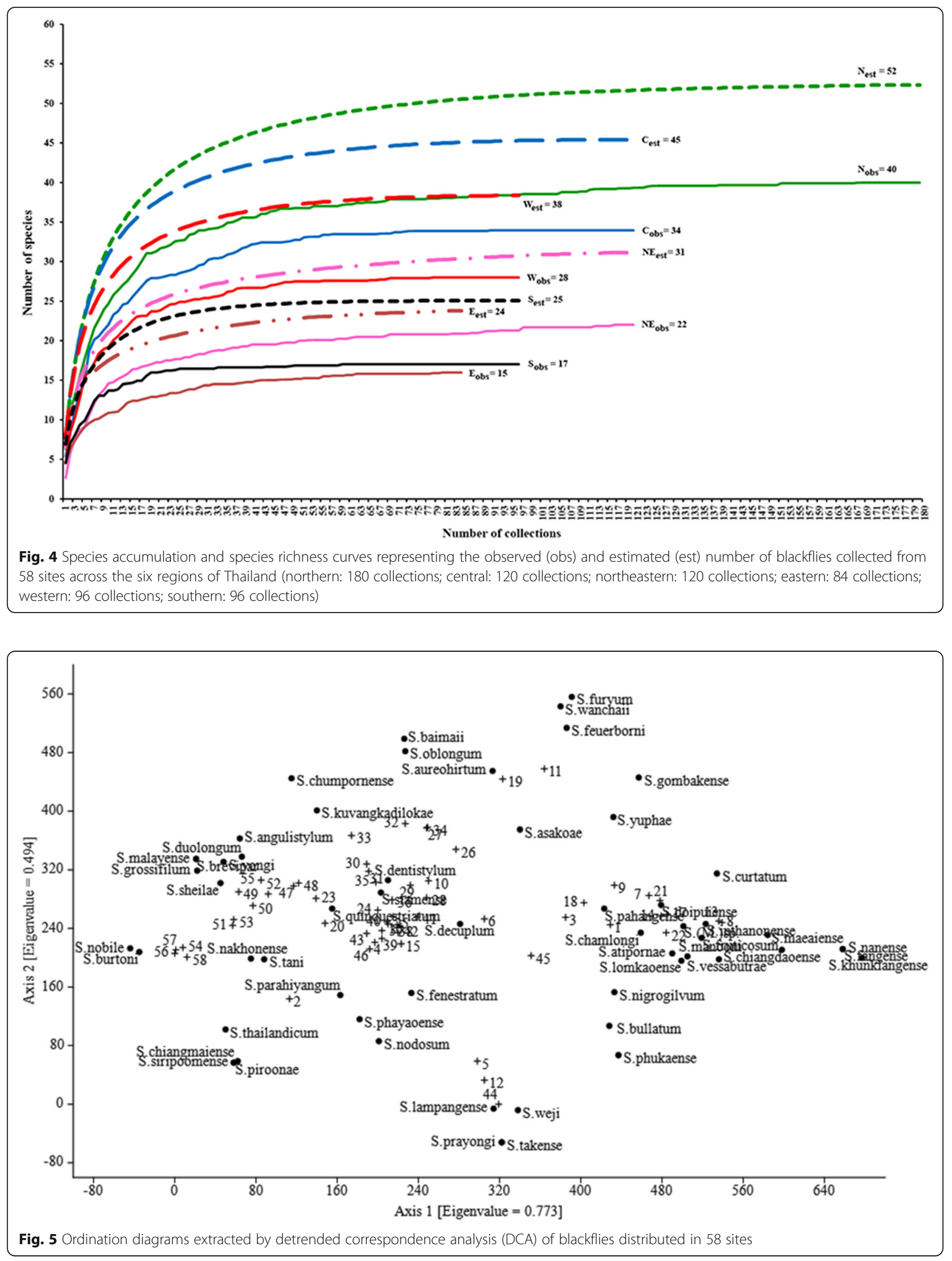

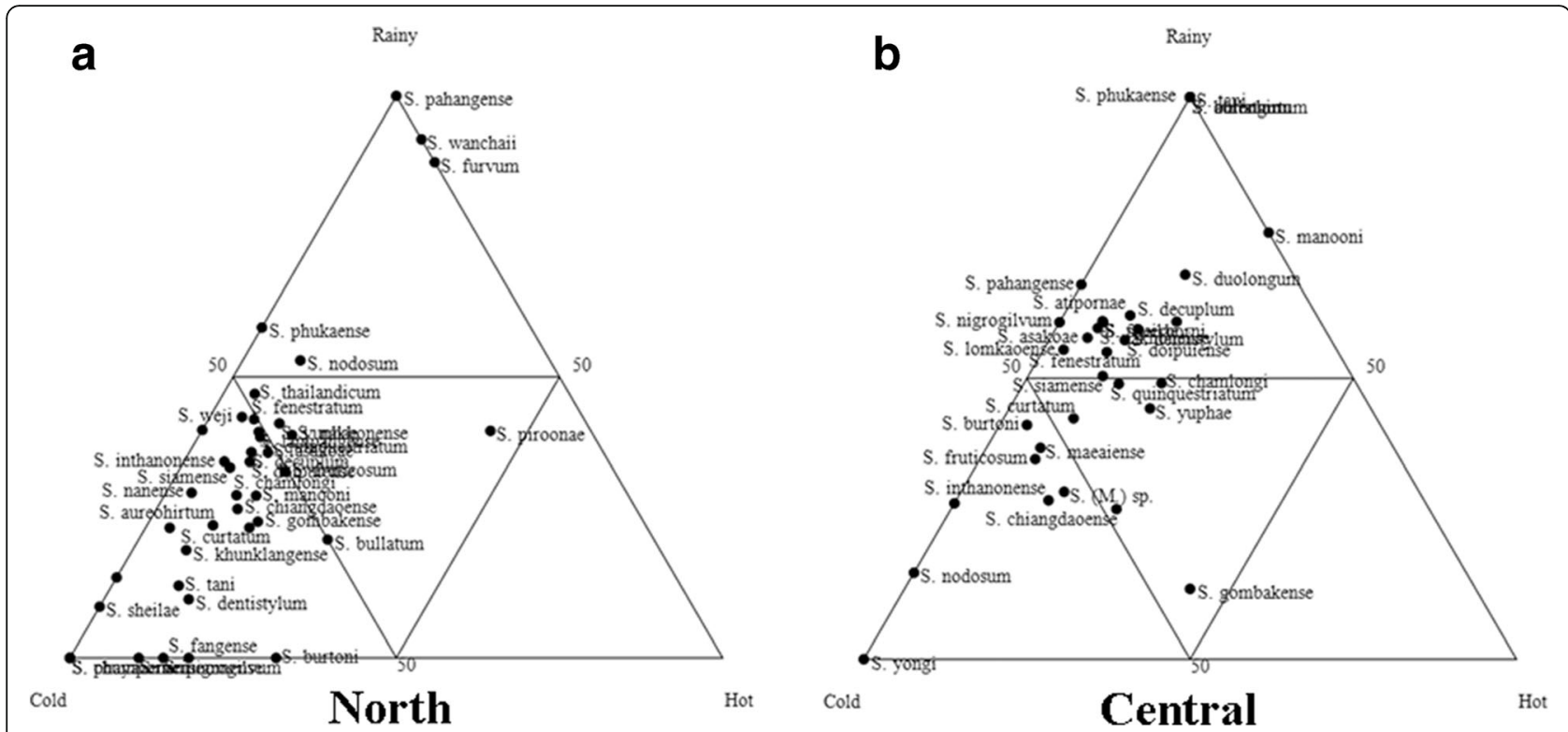

Fig. 6 Ternary plots representing the occurrence and seasonal abundance of blackflies in the northern (a) and central region (b) of Thailand

There were significant differences in the mean number of blackflies captured in the central region during the hot season, when compared to the rainy (Kruskal-Wallis test, $H=30.265, d f=2, P<0.0001)$ and cold seasons (KruskalWallis test, $H=19.456, d f=2, P=0.020$ ).

\section{Northeastern region}

The most frequent taxa at all sites were $S$. asakoae complex and S. siamense complex (100\%), followed by S. decuplum, S. fenestratum and S. quinquestriatum (90\%). In addition, the S. asakoae complex, S. oblongum, S. fenestratum, the $S$. siamense complex and $S$. quinquestriatum were the five predominant taxa, representing $15.7 \%$ $(n=415), 13.4 \%(n=353), 12.8 \%(n=338), 11 \%(n=290)$ and $8.3 \%(n=219)$, respectively (Additional file 6: Table S6). There was a significant difference in the mean number of blackflies collected among the three seasons (Kruskal-Wallis test, $H=28.687, d f=2, P<0.0001$ ).

\section{Eastern region}

The most frequent taxa at all sites were $S$. decuplum, $S$. dentistylum, the $S$. siamense complex, S. fenestratum and the $S$. tani complex (100\%), followed by the $S$.
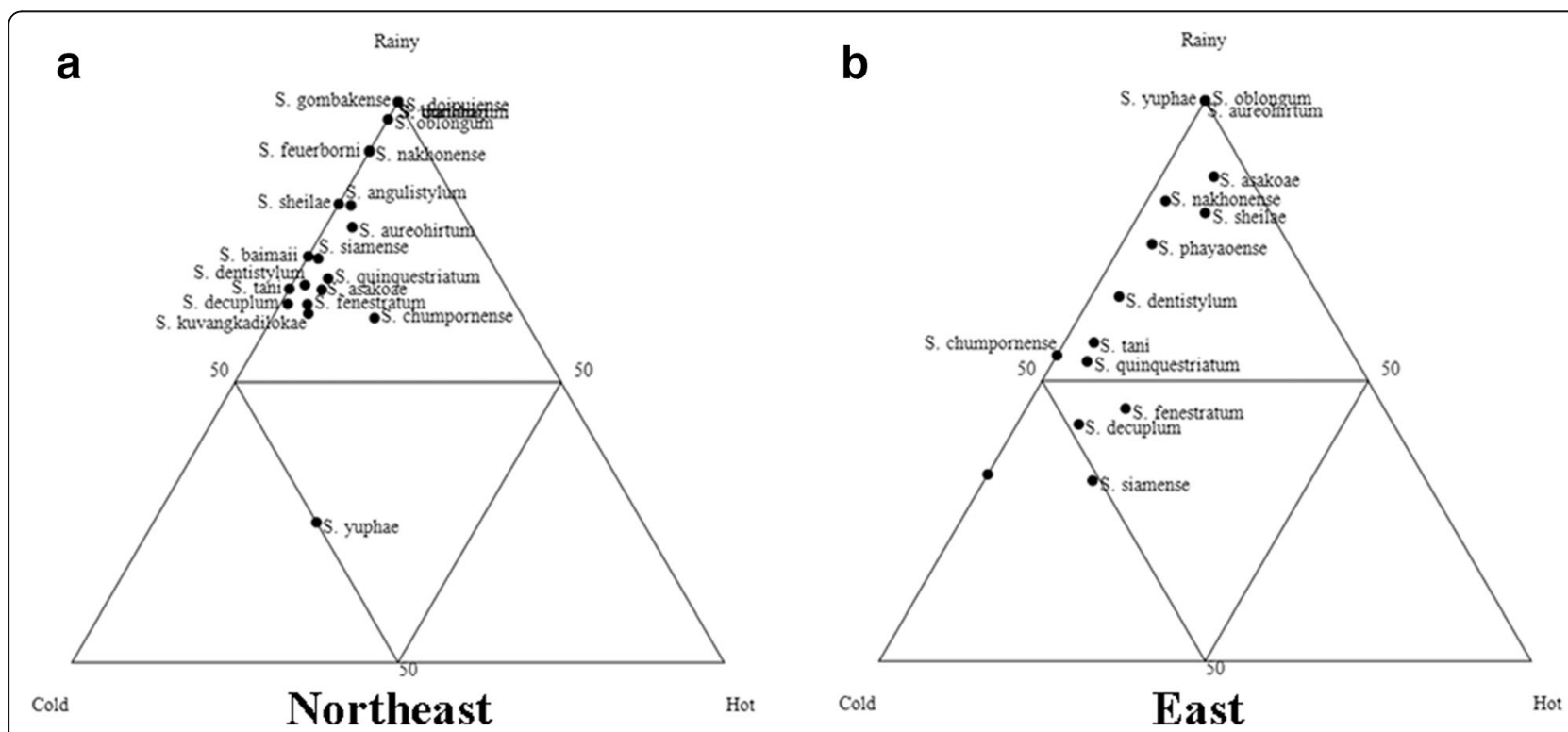

Fig. 7 Ternary plots representing the occurrence and seasonal abundance of blackflies in the northeastern (a) and eastern region (b) of Thailand 

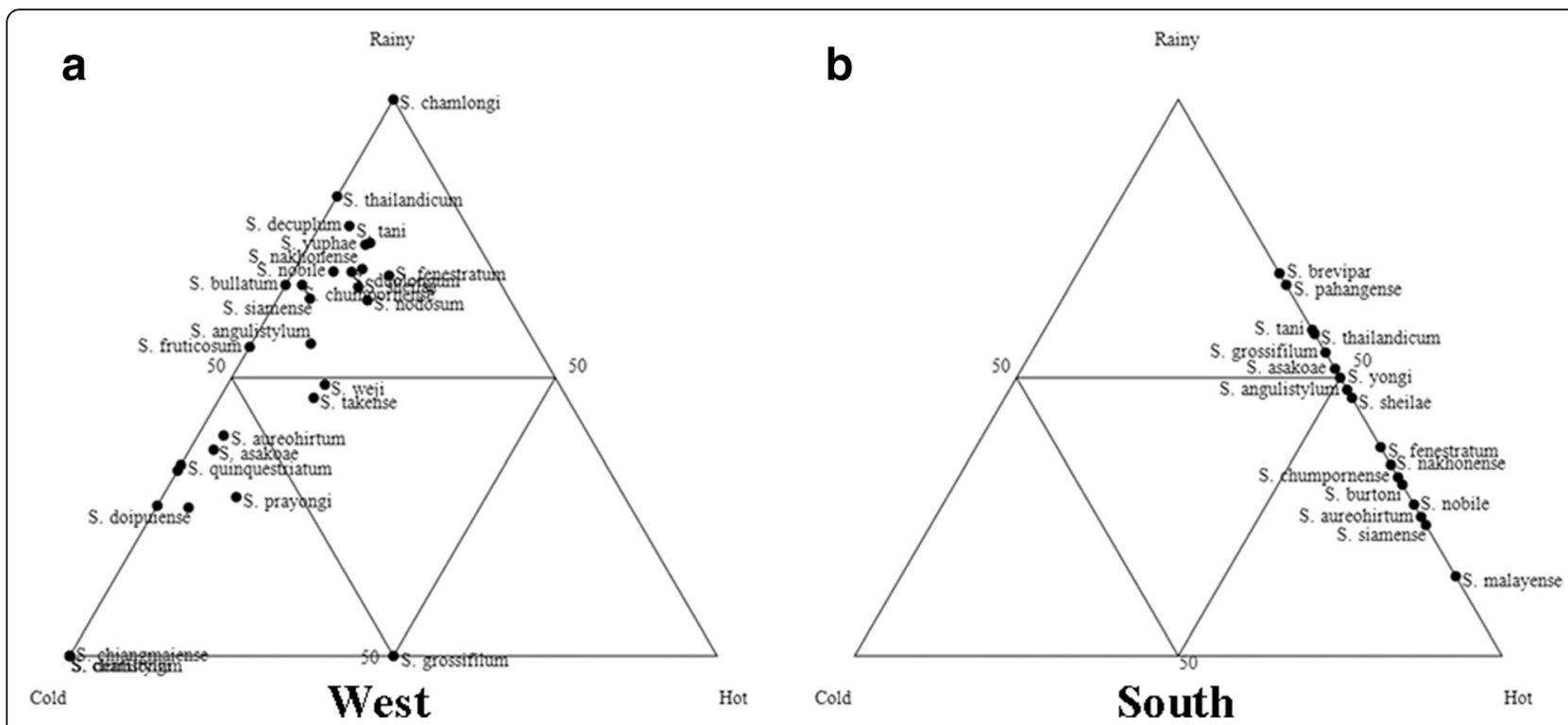

Fig. 8 Ternary plots representing the occurrence and seasonal abundance of blackflies in the western (a) and southern region (b) of Thailand

asakoae complex and S. nakhonense (85.7\%). Additionally, S. fenestratum, the S. siamense complex, S. decuplum, S. dentistylum and $S$. nakhonense were the five predominant taxa, representing 24\% ( $n=479), 19.6 \%(n=391), 18.5 \%$ $(n=369), 8.1 \%(n=163)$ and $7 \%(n=140)$, respectively (Additional file 7: Table S7). The mean number of blackflies captured in the hot season was lower than that in the rainy (Kruskal-Wallis test, $H=21.195, d f=2, P=0.021$ ) and cold season (Kruskal-Wallis test, $H=34.122, d f=2$, $P<0.0001)$. There was a significant difference in a mean number of the blackflies collected in this region between the hot and rainy seasons (Kruskal-Wallis test, $H=15.033, d f=2, P<0.005)$.

\section{Western region}

The most frequent taxa at all sites were $S$. nakhonense and S. tani complex (75\%), followed by the S. angulistylum complex, the S. asakoae complex, S. sheilae, the $S$. siamense complex and $S$. fenestratum (62.5\%). In addition, S. nakhonense, S. weji, the S. angulistylum complex, $S$. duolongum and the $S$. siamense complex were the five predominant taxa, representing $16.1 \%(n=548)$, $12 \%(n=406), 9.3 \%(n=317), 7.5 \%(n=255)$ and $6.5 \%$ $(n=221)$, respectively (Additional file 8 : Table S8). The mean number of blackflies captured was lower during the hot season than that during the rainy (Kruskal-Wallis test, $H=27.071, d f=2, P<0.0001)$ and cold season (Kruskal-Wallis test, $H=22.589, d f=2, P=0.002$ ).

\section{Southern region}

The most frequent taxa at all sites were S. burtoni, S. sheilae, S. nakhonense and S. nobile (100\%), followed by the S. asakoae complex and S. fenestratum (87.5\%).
Additionally, S. nobile, S. burtoni, S. nakhonense, S. sheilae and the $S$. asakoae complex were the five predominant taxa, representing $31.1 \%(n=746), 19.8 \%$ $(n=474), 12.4 \%(n=297), 12.1 \%(n=289)$ and $5.2 \%$ $(n=124)$, respectively (Additional file 9: Table S9). There were no significant differences in the mean number of blackflies captured between the hot and rainy seasons (Mann-Whitney $U$-test, $U=128.000, P=0.570$ ).

\section{Discussion}

Species composition, species richness, seasonal abundance and diversity

The number of blackflies reached its highest during the cold season, according to a previous report by Srisuka et al. [13], who studied the seasonal biodiversity of blackflies at Doi Pha Hom Pok, northern Thailand. The greatest number of blackflies in the southern region was in the hot season. This study found that seven of seventeen species identified from this region increased their populations approximately two to three times during this season. This observation agrees with the study of blackflies in northern Sweden, where they were higher in the summer than other seasons [29]. The highest number of blackflies collected from central, northeastern, eastern and western regions of Thailand peaked in the rainy season. The findings in this study were consistent with those in a previous report by Pramual \& Wongpakam [30], who studied the seasonal variation of blackflies at Phu Phan mountain range in northeastern Thailand. They demonstrated that the species abundance was higher in rainy seasons than in others and blackfly communities at each stream site varied with seasonality, i.e. S. nakhonense, the $S$. angulistylum complex and $S$. 
kuvangkadilokae were more dominant in the rainy season, whereas the $S$. asakoae complex, S. aureohirtum and $S$. trangense were dominant in the hot and cold season [30]. Likewise, blackflies were caught in higher numbers during the rainy season in Nigeria, Africa [31]. Takaoka [32] showed that seasonal abundance patterns of adult populations of $S$. ochraceum, the vector of onchocerciasis in Guatemala, Central America, differ by localities depending on the availability of permanent and temporary streams suitable for its immature stages.

In addition to seasons and geographical locations, elevation also can influence blackfly populations. The results of this study showed that the Shannon diversity index was highest in areas with high elevations, i.e. Rom Klao (1047 m), Doi Phu Kha (1629 m), Phu Ruea $(1337 \mathrm{~m})$ and Mae Wong $(1274 \mathrm{~m})$. It was found that 36 species manifested in optimal or unique environments that had suitable factors for their breeding habitats. For example, S. baimaii breeds at Phu Kradueng, Loei Province in only high mountains, with slow-flowing streams exposed to sunlight. Likewise, all species members in the subgenus Montisimulium are restricted to high elevations at Doi Inthanon National Park, Chiang Mai Province. In contrast, S. gombakense has a wide vertical distribution range from a height of $500 \mathrm{~m}$ in small streams in the foothills to $2100 \mathrm{~m}$ near the summit of Doi Pha Hom Pok National Park [13], and it is also found at an elevation of $412 \mathrm{~m}$ at Mae Klang Waterfall, Doi Inthanon National Park [33]. In addition, the S. asakoae complex, S. fenestratum, the S. siamense complex, S. decuplum, S. nakhonense, and the S. tani complex were the most common taxa found in this study, which is similar to previous reports by Pramual \& Kuvangkadilok [34], and Pramual \& Wongpakam [30].

\section{Relationship of subgenera to elevation}

The subgenus Asiosimulium is a small and endemic subgenus in the Oriental region. It is represented by four species, of which three, S. oblongum, S. wanchaii and $S$. furvum, have been reported in Thailand [35-37], and the remaining one, S. suchitrae, in Nepal [38]. The first three species were found in lowland streams, flowing slowly over rock surfaces exposed to the sun during the rainy season, while $S$. suchitrae was found at high elevation $(1826 \mathrm{~m})$ in a small stream flowing slowly over rocks [38]. Both S. furvum and S. wanchaii were restricted to their sites, but $S$. oblongum was distributed widely in and near the northeastern, central and eastern regions. The subgenus Daviesellum is represented by two species, S. pahangense and S. courtneyi, in Thailand [39]. Only S. pahangense was distributed at high elevation from northern to central regions along the boundary with Myanmar, and also in lowland streams in the southern region. Most species of Gomphostilbia, such as those of the S. batoense, S. ceylonicum, S. epistum, S. gombakense and $S$. varicorne species-groups, are the second largest subgenus in Thailand and distributed at low elevations. This study found S. sheilae, the S. siamense complex and $S$. chumpornense in all six regions of Thailand, with their breeding habitats mostly in lowland streams as previously reported $[7,30]$. In contrast, species of the $S$. asakoae and $S$. darjeelingense speciesgroups were found in highland streams, except for the $S$. asakoae complex, which was distributed widely from low elevations to $2500 \mathrm{~m}$ at the summit of Doi Inthanon National Park, Chiang Mai Province and in other Asian countries, such as Malaysia, China (Hong Kong) and Vietnam [7, 13, 21, 25, 40-42].

The subgenus Montisimulium is represented by six species in Thailand. Two of them, i.e. S. nanense and $S$. (Montisimulium) sp., were discovered in this study at high elevations, as reported by Takaoka \& Somboon [43] and Takaoka et al. [44], who collected three species of this subgenus at high elevations ranging from 2229 to $3720 \mathrm{~m}$ in Bhutan and $1750 \mathrm{~m}$ in Vietnam, respectively. The remaining species have been found only on Doi Inthanon and Doi Pha Hom Pok in Chiang Mai Province $[45,46]$. Of ten species of the subgenus, Nevermannia reported in Thailand, seven were found in this study. Most species were collected at high elevations, for example, the high mountains of Chiang Mai Province, northern Thailand [13, 26, 47, 48]. Other reports from several other Asian countries, such as Malaysia, Myanmar, Vietnam, Indonesia and Bhutan, indicated that members of this subgenus were associated with high elevations ranging from 1000 to $2532 \mathrm{~m}$ [43, 49-53]. The subgenus Simulium is the largest subgenus in Thailand, including 45 described species, of which 28 (62\% of total species) were collected. Most of the common taxa, such as S. fenestratum, S. nakhonense, S. quinquestriatum, and the S. tani complex, breed in lowland streams. The findings of this study were in accordance with those reported by Takaoka et al. [44], Srisuka et al. [13] and Pramual \& Wongpakham [30]. Species of the $S$. christophersi, S. malyschevi and S. variegatum speciesgroups were distributed in middle to high elevations $(1200-2200 \mathrm{~m})$, as previously studied in Vietnam and Thailand [44, 54]. In contrast, most of the species within the S. multistriatum, S. nobile and S. striatum speciesgroups occurred in lowland streams, as reported by Srisuka et al. [13] and Ishii et al. [17]. Members of the $S$. griseifrons species-group colonized streams at low to high elevations (200-2210 m).

\section{Conclusion}

The findings of this study demonstrated that the richness and relative abundance of blackflies were different between regions, and blackfly communities at each 
stream site varied with seasonality. Also, the elevation of sampling sites, which ranged from high mountainous to lowland streams as well as covering all mainland steams, influenced the distribution of blackflies in the country. Concurrent species, population dynamics and seasonal abundance in each area are important as useful information for pest species management and control programs, and especially for ecotourism in forests, by waterfalls and in high mountainous areas, where the number of tourists increases yearly.

\section{Additional files}

Additional file 1: Table S1. Names of sampling sites, geographical coordinates, altitudes, and environmental variables for blackfly collections at 58 sampling sites in six regions of Thailand. (DOCX $38 \mathrm{~kb}$ )

Additional file 2: Table S2. Diversity parameters for blackflies at 58 sampling sites in the six regions of Thailand. (DOCX $19 \mathrm{~kb}$ )

Additional file 3: Table S3. Seasonal abundance and species richness of blackfly species at 58 sampling sites representing six regions in Thailand. (DOCX $44 \mathrm{~kb}$ )

Additional file 4: Table S4. Regional distribution and relative abundance of blackflies at 15 sampling sites in northern Thailand. (DOCX $30 \mathrm{~kb}$ )

Additional file 5: Table S5. Regional distribution and relative abundance of blackflies at 10 sampling sites in central Thailand. (DOCX $24 \mathrm{~kb}$ )

Additional file 6: Table S6. Regional distribution and relative abundance of blackflies at 10 sampling sites in northeastern Thailand. (DOCX $20 \mathrm{~kb}$ )

Additional file 7: Table S7. Regional distribution and relative abundance of blackflies at 7 sampling sites in eastern Thailand. (DOCX $18 \mathrm{~kb}$ )

Additional file 8: Table S8. Regional distribution and relative abundance of blackflies at 8 sampling sites in western Thailand. (DOCX $21 \mathrm{~kb}$ )

Additional file 9: Table S9. Regional distribution and relative abundance of blackflies at 8 sampling sites in southern Thailand. (DOCX $19 \mathrm{~kb}$ )

\section{Abbreviations}

DCA: Detrended correspondence analysis; Exp H: Expected value of $\mathrm{H}$; Pielou J': evenness; $\mathrm{H}$ : Shannon-Wiener index

\section{Acknowledgements}

We are grateful to Dr Suyanee Vessabutr, Director of Queen Sirikit Botanic Garden, Chiang Mai, Thailand, for her interest and support in this study. Thanks go to Mr. Sumitr Suriya, Mr. Raewat Saokod, Ms. Sunantha Pilakantha and Ms. Chayanit Surin for their kind help in the field surveys and preparation of specimens in the laboratory. This article is dedicated to the late Professor Wej Choochote who kindly provided invaluable suggestions and supported this study.

\section{Funding}

This study was financially supported by the Thailand Research Fund (TRF Senior Research Scholar: grant number RTA5480006) to WC, and the Faculty of Medicine Research Fund, Chiang Mai University (CMU) to AS. This study was in part supported by the research grant from the Thailand Research Fund (TRF) and the Office of the Higher Education Commission (OHEC) through the Research Grant for New Scholar (grant number MRG5980101) to AS, and the University of Malaya (RP021A/16SUS) to HT.

\section{Availability of data and materials}

The data sets supporting the conclusions of this article are included within the article and its additional files.

\section{Authors' contributions}

WS and AS conceived and designed the study. WS and AS performed field and laboratory experiments, analyzed the data, interpreted the findings and wrote the manuscript. HT participated in species identification, data analysis and revised the manuscript. YO and MF helped to revise the manuscript. ST and KT participated in field experiments. All authors read and approved the final manuscript.

Ethics approval and consent to participate

Not applicable.

\section{Consent for publication}

Not applicable.

\section{Competing interests}

The authors declare that they have no competing interests.

\section{Publisher's Note}

Springer Nature remains neutral with regard to jurisdictional claims in published maps and institutional affiliations.

\section{Author details}

'Entomology Section, Queen Sirikit Botanic Garden, P.O. Box 7, Chiang Mai 50180, Thailand. ${ }^{2}$ Institute of Biological Sciences, Faculty of Science, University of Malaya, 50603 Kuala Lumpur, Malaysia. ${ }^{3}$ Research Center for the Pacific Islands, Kagoshima University, Kagoshima 890-8580, Japan. ${ }^{4}$ Division of Life Science Research, Research Promotion Institute, Oita University, Hasama, Oita 879-5593, Japan. ${ }^{5}$ Faculty of Veterinary Science, Prince of Songkla University, Songkhla 90110, Thailand. ${ }^{6}$ Faculty of Veterinary Medicine, Western University, Kanchanaburi 71170, Thailand. ${ }^{7}$ Department of Parasitology, Faculty of Medicine, Chiang Mai University, Chiang Mai 50200, Thailand.

Received: 9 March 2017 Accepted: 23 October 2017

Published online: 21 November 2017

\section{References}

1. Takaoka H. Insecta: Diptera, Simuliidae. In: Yule CM, Yong HS, editors. Freshwater invertebrates of the Malaysian region. Kuala Lumpur, Malaysia: The Academy of Sciences Malaysia; 2004. p. 673-82.

2. Srisuka W. Species diversity of black flies in Thailand, and the evaluation of ecological factors influencing black-fly species diversity in Doi Phahompok National Park. PhD Thesis, Chiang Mai University; 2015.

3. Murdock CC, Adler PH, Frank J, Perkins SL. Molecular analyses on host-seeking blackflies (Diptera: Simuliidae) reveal a diverse assemblage of Leucocytozoon (Apicomplexa: Haemospororida) parasites in an alpine ecosystem. Parasit Vectors. 2015;8:343.

4. Adler PH, Crosskey RW. World blackflies (Diptera: Simuliidae): A comprehensive revision of the taxonomic and geographical inventory. Available at: http://entweb.clemson.edu/biomia/pdfs/blackflyinventory.pdf. Accessed 20 Feb 2017.

5. Takaoka H, Otsuka Y, Choochote W, Thongsahuan S. Two new and one newly recorded species of Simulium (Gomphostilbia) (Diptera: Simuliidae) from southern Thailand. Med Entomol Zool. 2009;60:259-68.

6. Takaoka H, Otsuka Y, Choochote W, Thongsahuan S. A new species of Simulium (Simulium) (Diptera: Simuliidae) from southern Thailand. Med Entomol Zool. 2010;61:17-25.

7. Jitklang S, Kuvangkadilok C, Baimai V, Takaoka H, Adler PH. Cytogenetics and morphotaxonomy of the Simulium (Gomphostilbia) ceylonicum species group (Diptera: Simuliidae) in Thailand. Zootaxa. 2008;1917:1-28.

8. Huang YT, Phasuk J, Chanpaisaeng J, Adler PH. A new species of black fly in the subgenus Simulium (Diptera: Simuliidae) from Thailand. Med Entomol Zool. 2010;61:49-58.

9. Takaoka H, Srisuka W, Otsuka Y, Choochote W. A new species and species-group of Simulium (Simulium) (Diptera: Simuliidae) from Thailand. J Med Entomol. 2014; 51:725-32.

10. Takaoka H, Srisuka W, Saeung A, Otsuka Y, Choochote W. Simulium (Simulium) lomkaoense, a new species of black fly (Diptera: Simuliidae) from Thailand. J Med Entomol. 2014;51:1109-15.

11. Pramual P, Tangkawanit U. A new species of Simulium (Gomphostilbia) (Diptera: Simuliidae) from northeastern Thailand. Med Entomol Zool. 2008; 59:297-303.

12. Takaoka H, Srisuka W. Description of the female of Simulium (Gomphostilbia) kuvangkadilokae (Diptera: Simuliidae) from Thailand. Med Entomol Zool. 2010;61:39-47. 
13. Srisuka W, Takaoka H, Otsuka Y, Fukuda M, Thongsahuan S, Taai K, et al. Seasonal biodiversity of black flies (Diptera: Simuliidae) and evaluation of ecological factors influencing species distribution at Doi Pha Hom Pok National Park, Thailand. Acta Trop. 2015;149:212-9.

14. Choochote W, Takaoka H, Fukuda M, Otsuka Y, Aoki C, Eshima N. Seasonal abundance and daily flying activity of black flies (Diptera: Simuliidae) attracted to human baits in Doi Inthanon National Park, northern Thailand Med Entomol Zool. 2005;56:335-48.

15. Ittiponpanya N. A whole-year study of the flying activity of black fly attracted to humans in Doi Suthep-Pui National Park. MSc Thesis, Chiang Mai University; 2006.

16. Srisuka W. Life history and morphology of some black flies species at Mae Aeb Nai Village, ban Laung subdistrict, Chom thong district, Chiang Mai province, MSc Thesis, Chiang Mai University; 2007.

17. Ishii Y, Choochote W, Bain O, Fukuda M, Otsuka Y, Takaoka H. Seasonal and diurnal biting activities and zoonotic filarial infections of two species (Diptera: Simuliidae) in northern Thailand. Parasite. 2008;15:121-9.

18. Takaoka $\mathrm{H}$, Choochote W. A list of and keys to black flies (Diptera: Simuliidae) in Thailand. Trop Med HIth. 2004;32:189-97.

19. Edwards FW. The Simuliidae (Diptera) of Java and Sumatra. Arch Hydrobiol. 1934;13(Suppl. 5):92-138.

20. Takaoka H. The black files of Taiwan (Diptera: Simuliidae). Pacific Insects. 1979;20:365-403.

21. Takaoka H, Davies DM. The black flies (Diptera: Simuliidae) of West Malaysia. Fukuoka, Japan: Kyushu University Press; 1995. 175 pp.

22. Takaoka H, Srisuka W. Simulium (Nevermannia) vessabutrae sp. nov. (Diptera: Simuliidae) from Thailand. Med Entomol Zool. 2010;61:97-104.

23. Takaoka H, Srisuka W. Description a new species of Simulium (Montisimulium) (Diptera: Simuliidae) from Thailand. Med Entomol Zool. 2010;61:261-4.

24. Takaoka H, Srisuka W. A new species of Simulium (Nevermannia) (Diptera: Simuliidae) from Thailand, with keys to members of the Simulium feuerborni species group in Thailand. ZooKeys. 2011;89:57-70.

25. Takaoka H, Suzuki H. The black flies (Diptera: Simuliidae) from Thailand. Jpn J Sanit Zool. 1984;35:7-45.

26. Takaoka H, Srisuka W, Saeung A, Otsuka Y, Choochote W. Simulium (Nevermannia) chomthongense, a new species of black fly (Diptera: Simuliidae) from Chiang Mai. Thailand Trop Biomed. 2012;29:381-90.

27. Seaby RM, Henderson PA. Species diversity and richness version 4. 2016. Pisces conservation Ltd., Lymington, England.

28. Hammer O, Harper DAT, Ryan PD. PAST: paleontological statistics software package for education and data analysis. Palaeontol Electron. 2001:4:1-9.

29. Malmqvist $B$, Zhang $Y$, Adler PH. Diversity, distribution and larval habitats of north Swedish blackflies (Diptera: Simuliidae). Freshwat Biol. 1999:42:301-14.

30. Pramual P, Wongpakam K. Seasonal variation of black fly (Diptera: Simuliidae) species diversity and community structure in tropical streams of Thailand. Entomol Sci. 2010;13:17-28.

31. Akpan SS, Alaribe AAA, Ejezie GC. The distribution of black flies (Simulium species) in Ugbem and Ukwepeyiere communities of Biase local Govt, area of Cross River state. Nigeria J Dental Med Sci. 2012;1:24-8.

32. Takaoka $\mathrm{H}$. Seasonal occurrence of Simulium ochraceum, the principal vector of Onchocerca volvulus in the southeastern endemic area of Guatemala. Am J Trop Med Hyg. 1981;30:1121-32.

33. Takaoka H, Srisuka W, Saeung A. Description of the female of Simulium (Gomphostilbia) gombakense (Diptera: Simuliidae) from Thailand. Med Entomol Zool. 2010;61:111-4.

34. Pramual P, Kuvangkadilok C. Agricultural land use and black fly (Diptera, Simuliidae) species richness and species assemblages in tropical streams. Northeastern Thailand Hydrobiologia. 2009;625:173-84.

35. Takaoka $H$, Choochote W. A new subgenus and a new species of Simulium s.I. (Diptera: Simuliidae) from Thailand. Med Entomol Zool. 2005:56:33-41.

36. Takaoka $\mathrm{H}$, Choochote W. A new species of the subgenus Simulium (Asiosimulium) (Diptera: Simuliidae) from Thailand. Med Entomol Zool. 2006;57:45-8.

37. Takaoka H, Srisuka W, Saeung A, Choochote W. Simulium (Asiosimulium) furvum, a new species of black fly (Diptera: Simuliidae) from Thailand. J Med Entomol. 2013:50:493-500.

38. Takaoka H, Shrestha S. New species of black flies (Diptera: Simuliidae) from Nepal. Zootaxa. 2010;2731:1-62

39. Takaoka H, Adler PH. A new subgenus, Simulium (Daviesellum), and a new species, S. (D.) courtneyi, (Diptera: Simuliidae) from Thailand and Penninsular Malaysia. Jpn J Trop Med Hyg. 1997;25:17-27.

40. Takaoka H, Saito K. A new species and new records of black flies (Diptera: Simuliidae) from Thailand. Jpn J Trop Med Hyg. 1996;24:163-9.
41. Takaoka H. Morphotaxonomic revision of Simulium (Gomphostilbia) (Diptera: Simuliidae) in Oriental Region. Zootaxa. 2012;3577:1-42.

42. Low VL, Adler PH, Sofian-Azirun M, Srisuka W, Saeung A, Huang YT, et al. A multi-locus approach resolves the phylogenetic relationships of the Simulium asakoae and Simulium ceylonicum species groups in Malaysia: evidence for distinct evolutionary lineages. Med Vet Entomol. 2015;29:330-7.

43. Takaoka H, Somboon P. Eleven new species and one new record of black flies (Diptera: Simuliidae) from Bhutan. Med Entomol Zool. 2008;59:213-62.

44. Takaoka H, Sofian-Azirun M, Ya'cob Z, Chen CD, Lau KW, Low VL, et al. The black flies (Diptera: Simuliidae) of Vietnam. Zootaxa. 2017:4261:1-165.

45. Takaoka H, Choochote W. Two new species of Simulium (Montisimulium) (Diptera: Simuliidae) from northern Thailand. Med Entomol Zool. 2005;56: 21-31.

46. Takaoka H. Choochote W. Discovery of two more new species of Simulium (Montisimulium) (Diptera: Simuliidae) in Doi Inthanon National Park, Chiang Mai, Thailand. Trop Med Hlth. 2005;33:209-15.

47. Takaoka H, Choochote W. Two new species of Simulium (Nevermannia) (Diptera: Simuliidae) from northern Thailand. Trop Med HIth. 2005;33:133-41.

48. Takaoka H, Srisuka W. Simulium (Nevermannia) wichaii, a new black fly species (Diptera: Simuliidae) from northern Thailand. Med Entomol Zool. 2010;61:273-9.

49. Ya'cob Z, Takaoka H, Low VL, Sofian-Azirun M. Uncovering the mask of the Simulium feuerborni Complex (Diptera: Simuliidae): description of a new pseudocryptic species Simulium pairoti from Malaysia. Acta Trop. 2017;169: 133-41.

50. Ya'cob Z, Takaoka H, Sofian-Azirun M. Simulium ledangense, a new species of the Simulium feuerborni species-group of the subgenus Nevermannia (Diptera: Simuliidae) from Mount Ledang, Peninsular Malaysia. Zootaxa. 2014;3881(3):228-36.

51. Takaoka H. Notes on blackflies (Diptera: Simuliidae) from Myanmar (formerly Burma). Japan. J Trop Med Hyg. 1989;17:243-57.

52. Takaoka H, Sofian-Azirun M, Ya'cob Z, Chen CD, Lau KW, Pham XD. The black flies (Diptera: Simuliidae) from Thua Thien Hue and Lam Dong provinces, Vietnam. Zootaxa. 2015;3961:1-96.

53. Takaoka H, Davies MDA. New black flies species of Simulium (Nevermannia) from Sumatra, Indonesia. Jpn J Trop Med Hyg. 1995;23:127-31.

54. Takaoka H, Srisuka W, Saeung A. Two new species of the Simulium (Simulium) variegatum species-group of black flies (Diptera: Simuliidae) from Thailand. Med Entomol. 2017:54:1213-23.

\section{Submit your next manuscript to BioMed Central and we will help you at every step:}

- We accept pre-submission inquiries

- Our selector tool helps you to find the most relevant journal

- We provide round the clock customer support

- Convenient online submission

- Thorough peer review

- Inclusion in PubMed and all major indexing services

- Maximum visibility for your research

Submit your manuscript at www.biomedcentral.com/submit 